\title{
THE COLLOQUIUM PUBLICATIONS
}

The Council of the American Mathematical Society has adopted an extension of its policy with regard to the Colloquium series of publications, and has appointed the undersigned editorial committees to initiate this extension of policy.

In the past the Colloquium lectures have been given by lecturers invited for the purpose by the Council and the books published in the Colloquium series have been reports of these lectures. In the future it is intended to continue this plan unaltered but also to include, if possible, in the series a number of monographs and expositions of new mathematical developments which may be submitted by their authors on their own initiative without special invitation from the Council. The committee will, therefore, be glad to consider manuscripts which will occupy not more than 200 pages in book form. When suitable occasions of the nature of colloquia or symposia present themselves, the authors of accepted manuscripts may be invited to present their results in the form of lectures or series of lectures at meetings of the Society. The final acceptance of any manuscript and the appointment of any lecturer must, in each case, be confirmed by the Council of the Society.

$\mathrm{Up}_{\mathrm{p}}$ to the present time six volumes have been published in the series of colloquium publications. Future volumes will be published in the order of acceptance of the manuscripts in final form for publication, and each monograph will be bound separately instead of in a volume with the lectures of other Colloquium speakers as heretofore.

It is now the policy of the Society that all proceeds from the sales of old Colloquia shall go to the Colloquium Fund and be used to defray the expenses of the publication of new Colloquia. Members of the Society and other interested persons who do not have complete sets of the Colloquia already published are invited to purchase copies and thus to help in an enterprise which is of the utmost importance to mathematics. G. D. Birkhoff G. A. Bliss Oswald Veblen (Chairman) 